\title{
Empirical research of meteorological science \& technology innovation ability based on data analysis
}

\author{
Danna Shen ${ }^{1, *}$, Danhong Shen ${ }^{2}$, and Yan $\mathrm{Li}^{3}$ \\ ${ }^{1}$ Development Research Center of China Meteorological Administration, Beijing 100081, China \\ ${ }^{2}$ North University of China, China \\ ${ }^{3}$ Zhongnan University of Economics and Law, China
}

\begin{abstract}
Based on the status quo of the meteorological S\&T innovation of 31 provinces and cities in China, this paper sets up the meteorological S\&T evaluation index system on the basis of the meteorological statistics data in 2015. It also builds the innovation ability evaluation model of meteorological S\&T based on AHP. Then it compares and analyzes the results, which provides perspectives for the accurate understanding of innovation ability of meteorological S\&T in China. At last, it put forwards some suggestions to improve the S\&T ability, i.e., enhance the policy direction, coordinate S\&T innovation ability among different regions, strengthen the S\&T input to the basic $R \& D$, pay attention to the opening and sharing of meteorological data, consolidate the leading role of enterprises in S\&T innovation.
\end{abstract}

\section{Introduction}

S\&T innovation, a constantly developing concept, is the creation process of new values in which the scientific discoveries and technological inventions are applied to the production system[1]. Meteorological S\&T is an important component in the S\&T innovation system. For instance, the meteorological forecasting directly influences the national ability of preventing disasters and reducing damages as well as coping with the climate changes. Developing and utilizing the climate resources is closely related to the national economic and social safety and healthy life of its people. Meanwhile, each major progress made by the meteorological cause cannot be separated from the major breakthrough of scientific technologies. It is obvious to see that the accuracy of meteorological forecasting greatly promotes the progress and development of meteorological S\&T. Therefore, the research of meteorological S\&T innovation is of great importance.

S\&T evaluation is an important way of assessing the effects of S\&T innovation.Under the guidance of innovation theories, some well-known international organizations have also evaluated the innovation ability. 2017 Global Innovation Index Report issued by WIPO analyzes the global innovation ability[2]. 2017 Nature Index Rankings issued by Nature ranks the global frontier organizations of basic researches concerning their annual performances in terms of paper output. Foreign meteorological organizations also attach

* Corresponding author: s.dn@163.com 
great importance to evaluating the innovation ability of meteorological S\&T. NOAA issued the 2016 report of chief scientists in 2017, which not only analyzes and determines the seven fields of advantageous subjects of NOAA with bibliometrics as the evidence but also conducts in-depth analysis of human resource conditions of NOAA. Australian scientists starts the censorship of the ability evaluation of the climatic science in 2016, so as to determine the current climatic science ability of Australia.

Chinese scholars have also made evaluation researches of S\&T to some extent. The first type is to study the regional innovation. For example, Lu Shan[3], Zhang Xuping evaluate the regional innovation appraisal system and innovation ability. Fan Hong evaluates the relative efficiency of S\&T input and output in Guangdong Province based on DEA method. Fan Hua[4] and Song Jiekun[5] study the efficiency and its influence of S\&T in several provinces of China. The third type is to evaluate the S\&T innovation ability from the perspective of the industry.

In summary, scholars all over the world have conducted numerous researches about the innovation ability, covering the fields including maritime, agriculture and university. It is a pity that meteorological field is not touched. The only few research papers related to meteorological S\&T are mostly centered on the policy suggestions, lacking of quantitative evaluation of meteorological S\&T innovation ability. Meteorology is a subject that is highly dependent on technology, data and calculations, however, the economic effects of meteorological S\&T innovations are difficult to evaluate. Consequently, it is not possible to copy the evaluation models of S\&T innovation ability in other fields to meteorology, plus the difficulty that some existing evaluation indexes have no good access to meteorological data source. All these discussed factors call for the need to establish a specific evaluation index system that suits the special rules of meteorology, so it can be used to assess the S\&T ability of meteorology. Therefore, on the basis of data statistics, the writer constructs the innovation ability indexes and evaluates the innovation ability of meteorological S\&T in 31 provinces and cities in China through the AHP and comprehensive scoring methods, and finally present suggestions according to the evaluation results.

\section{Constructing evaluation model of meteorological S\&T}

\subsection{Establishment of innovation ability index system of meteorological S\&T}

Judging from the connotation and meaning of S\&T innovation, the selection of evaluation indexes has firstly taken in account the statements by different scholars, including the global innovation index, national and urban innovation abilities. Finally, an evaluation index model of meteorological S\&T innovation ability is established, comprised of Level I Indexes of 4 items and Level II Indexes of 17 items (see Table 1). The evaluation indexes studied in this paper are not limited to the traditional measuring ones, such as number of paper and patent, but also focus on the human, environment, innovation openness and cooperation degree and innovation vigor in S\&T innovation. The results not just pay attention to the ranking of the areas, but also emphasize how to improve the process. Moreover, it aims to reflect the main determining factors through the results, so as to better measure and understand the innovation of meteorological S\&T.

\subsection{Weight determination of innovation ability of meteorological S\&T}

Based on the principle of Analytic Hierarchy Process (AHP)[6] and the evaluation indicator model, a judgment matrix is constructed. Through the design of questionnaire, totally 10 experts were selected to score the weight of each index. These experts' background 
information is as follows: 2 researchers with meteorological research background, 4 associate researchers with meteorological background, 2 associate researchers with management background, 2 Ph.D. candidates working in meteorological services and disasters. As the objective evaluation method is based on the original data, the calculation results vary with original data difference. Considering the stability of the results, this paper selects the subjective evaluation method for analysis. According to their own experience and understanding of every indicator, each expert gives a mark according to the judgment matrix scoring table, and construct a judgment matrix.

The qualitative results are converted into quantitative data by using scales of 1 to 9 . Finally, the hierarchical single ranks of both Level I and II indicators are obtained.

Using mathematical calculations to conduct hierarchical rank with the judgment matrix filled by experts, actually it is to calculate the weight vectors. The eigenvalue method is selected for this study. The specific steps are as follows: (1) judge matrix normalization: $B_{\mathrm{ij}}=\frac{a_{i j}}{\sum_{i=1}^{n} a_{i j}}$, where $a_{i j}$ is the element of the judgment matrix; (2) calculate the weight of each factor: $W_{\mathrm{j}}=\frac{\sum_{j=1}^{n} b_{i j}}{\sum_{i=1}^{n} \sum_{j=1}^{n} b_{i j}}$, where $b_{i j}$ is the element of the norm lized judgment matrix; (3) calculate the eigenvalue of the judgment matrix: $\lambda_{\mathrm{i}}=\sum_{j=1}^{n} a_{i j} W_{j}$, where $W_{\mathrm{j}}$ is the weight of each factor; (4) calculate the max eigenvalue of the judgment matrix: $\lambda_{\max }=\sum_{i=1}^{n} \frac{\lambda_{i}}{n W_{i}}$, where $\lambda_{i}$ is the eigenvalue of each factor, $W_{i}$ is the weight of each factor, $\mathrm{n}$ is the number of the factor.

In the hierarchical ranking, the consistency of results is checked and the rationality of the judgment matrix judged. The specific steps are as follows: (1) calculate the consistency index $\mathrm{CI}: \quad C I=\frac{\lambda_{\max }-n}{n-1}$, where $\lambda_{\max }$ is the $\max$ eigenvalue of each factor, $\mathrm{n}$ is the number of the factors; (2) calculate the random consistency ratio $\mathrm{CR}: \mathrm{CR}=\mathrm{CI} / \mathrm{RI}$, where $\mathrm{RI}$ is a random consistency index, according to the order of the judgment matrix, looking up the table obtained when $\mathrm{CR}<0.1$, consistency test passed, indicating that it is available to see eigenvector as weight vector.

The writer adopts the proportion scale from 1 to 9 to turn the qualitative results into quantitative data. Finally, the single hierarchical arrangement of Level I Indexes and Level II Indexes are drawn. The weight results are shown as follows (Table 1):

Table 1. Weight Scores of Indexes of Various Levels.

\begin{tabular}{|c|c|}
\hline \multicolumn{2}{|c|}{ Level I Index } \\
\hline Meteorological S\&T innovation ability & Weight \\
\hline S\&T innovation environment & 0.3 \\
\hline S\&T innovation input & 0.3 \\
\hline S\&T innovation output & 0.27 \\
\hline S\&T innovation efficiency & 0.13 \\
\hline Level II Index \\
\hline
\end{tabular}




\begin{tabular}{|c|c|}
\hline S\&T innovation environment & weight \\
\hline Number of meteorological scientific research organization & 0.14 \\
\hline Number of professional meteorological technicians in 10,000 people & 0.31 \\
\hline Employees with the master's degree and above in the employment team, \% & 0.17 \\
\hline Activeness of trans-provincial meteorological data & 0.11 \\
\hline volume of meteorological data sharing services & 0.27 \\
\hline S\&T innovation input & weight \\
\hline Expenditure on meteorological R\&D, \% GDP & 0.18 \\
\hline Annual growth rate of meteorological R\&D expenditure, $\%$ & 0.17 \\
\hline $\begin{array}{l}\text { Meteorological S\&T expenditure by professionals per capita, Chinese Yuan } \\
\text { (RMB) }\end{array}$ & 0.20 \\
\hline Basic research on R\&D, \% & 0.21 \\
\hline Applied research on $\mathrm{R} \& \mathrm{D}, \%$ & 0.24 \\
\hline S\&T innovation output & weight \\
\hline Number of papers in 10,000 researchers & 0.3 \\
\hline Number of patent in 10,000 researchers & 0.2 \\
\hline Number of undertaken projects per capita & 0.14 \\
\hline Project participating staff in total employees, $\%$ & 0.18 \\
\hline Number of awards per capita & 0.18 \\
\hline S\&T innovation efficiency & weight \\
\hline Annual commercialization rate of meteorological S\&T findings, $\%$ & 0.55 \\
\hline Number of commercialization S\&T findings & 0.45 \\
\hline
\end{tabular}

\subsection{Data sources}

The data used in this paper is mainly selected from publications including China Meteorological Statistical Yearbook, Annual Report on China Meteorological Science And Technology Statistics, and China Meteorological Development Report. However, only the statistical data in 2015 was finally chosen and applied for the analysis process in this article, because of the problems that not only the statistical indexes are not the same in different years, but also even the same indexes are not continuous in series years due to lack of some data. It is notable to explain that the S\&T research articles in 10,000 people means the SCI articles in 10,000 people, and awards per capita means the national prizes won by each 
province.

\subsection{Construction of evaluation model of meteorological S\&T innovation ability}

After the evaluation indexes and weights are determined, the comprehensive scoring method is adopted to conduct empirical researches of innovation ability of meteorological S\&T in 31 provinces across China in the year of 2015:

1. Conduct standardized treatment of the primitive data

Considering that the indexes involved in this research are positive ones, the writer adopts the formula $Z_{i j}=\frac{X_{i j}-\min X_{i j}}{\max X_{i j}-\min X_{i j}}$ to conduct standardized treatment of data, among which $X_{i j}$ represents the primitive data, $\max X_{i j}$ the maximum value and min $X_{i j}$ the minimum value respectively.

2. Calculate the scores of S\&T innovation environment with the formula of $S=\sum_{i=1}^{n} W_{j} Z_{i j}$, where $W_{j}$ is the weight of determining factors, $Z_{i j}$ the standardized data, and $\mathrm{S}$ the score of $\mathrm{S} \& \mathrm{~T}$ innovation environment in different provinces.

3. The scores of S\&T innovation input, output and efficiency are calculated in the same method. Finally, the writer ranks the scores after calculating the scores of the innovation abilities in different provinces according to the weights of S\&T innovation environment, input, output and efficiency.

\section{Empirical analysis of innovation ability of meteorological S\&T}

Through the standardized treatment of data and by applying the evaluation model, the scores of indexes of various levels and total scores of S\&T innovation ability in 31 provinces are calculated. The total scores of 31 provinces are sorted by size and the results are shown in the following Table 2.

Table 2. Comprehensive Evaluation of Innovation Ability of Meteorological S\&T in China.

\begin{tabular}{|c|c|c|c|c|c|c|}
\hline Region & $\begin{array}{c}\text { S\&T } \\
\text { Innovation } \\
\text { Environment }\end{array}$ & $\begin{array}{c}\text { S\&T } \\
\text { Innovation } \\
\text { Input }\end{array}$ & $\begin{array}{c}\text { S\&T } \\
\text { Innovation } \\
\text { Output }\end{array}$ & $\begin{array}{c}\text { S\&T } \\
\text { Innovation } \\
\text { Efficiency }\end{array}$ & $\begin{array}{c}\text { Total } \\
\text { Scores }\end{array}$ & Rankin' \\
\hline $\begin{array}{c}\text { Average } \\
\text { Value }\end{array}$ & 0.28 & 0.37 & 0.27 & 0.26 & 0.30 & - \\
\hline Shanghai & 0.40 & 0.59 & 0.64 & 0.43 & 0.53 & 1 \\
\hline Beijing & 0.28 & 0.53 & 0.42 & 0.64 & 0.44 & 2 \\
\hline Guangdong & 0.41 & 0.37 & 0.36 & 0.74 & 0.43 & 3 \\
\hline Zhejiang & 0.24 & 0.36 & 0.50 & 0.70 & 0.41 & 4 \\
\hline Gansu & 0.27 & 0.68 & 0.30 & 0.13 & 0.38 & 5 \\
\hline Jiangsu & 0.54 & 0.26 & 0.44 & 0.11 & 0.37 & 6 \\
\hline Hainan & 0.28 & 0.52 & 0.37 & 0.23 & 0.37 & 7 \\
\hline Shaanxi & 0.24 & 0.37 & 0.31 & 0.75 & 0.36 & 8 \\
\hline
\end{tabular}




\begin{tabular}{|c|c|c|c|c|c|c|}
\hline Xinjiang & 0.38 & 0.40 & 0.40 & 0.13 & 0.36 & 9 \\
\hline Anhui & 0.25 & 0.32 & 0.37 & 0.45 & 0.33 & 10 \\
\hline Yunnan & 0.50 & 0.39 & 0.17 & 0.04 & 0.32 & 11 \\
\hline Sichuan & 0.44 & 0.32 & 0.15 & 0.37 & 0.32 & 12 \\
\hline Tianjin & 0.21 & 0.37 & 0.36 & 0.24 & 0.30 & 13 \\
\hline Hubei & 0.36 & 0.28 & 0.31 & 0.13 & 0.29 & 14 \\
\hline $\begin{array}{c}\text { Inner } \\
\text { Mongolia }\end{array}$ & 0.43 & 0.39 & 0.07 & 0.19 & 0.29 & 15 \\
\hline Hebei & 0.25 & 0.31 & 0.23 & 0.46 & 0.29 & 16 \\
\hline Shanxi & 0.24 & 0.41 & 0.23 & 0.20 & 0.28 & 17 \\
\hline Hunan & 0.31 & 0.38 & 0.23 & 0.09 & 0.28 & 18 \\
\hline Guangxi & 0.26 & 0.27 & 0.30 & 0.26 & 0.27 & 19 \\
\hline Jiangxi & 0.22 & 0.40 & 0.28 & 0.05 & 0.27 & 20 \\
\hline Liaoning & 0.26 & 0.39 & 0.22 & 0.00 & 0.25 & 21 \\
\hline Shandong & 0.31 & 0.33 & 0.12 & 0.22 & 0.25 & 22 \\
\hline Jilin & 0.25 & 0.29 & 0.16 & 0.34 & 0.25 & 23 \\
\hline Henan & 0.26 & 0.31 & 0.14 & 0.32 & 0.25 & 24 \\
\hline Guizhou & 0.19 & 0.32 & 0.26 & 0.18 & 0.25 & 25 \\
\hline Fujian & 0.21 & 0.30 & 0.19 & 0.31 & 0.24 & 26 \\
\hline $\begin{array}{c}\text { Heilongjia } \\
\text { ng }\end{array}$ & 0.21 & 0.31 & 0.17 & 0.19 & 0.23 & 27 \\
\hline Ningxia & 0.12 & 0.41 & 0.15 & 0.10 & 0.21 & 28 \\
\hline Chongqing & 0.17 & 0.24 & 0.21 & 0.16 & 0.20 & 29 \\
\hline Qinghai & 0.12 & 0.39 & 0.12 & 0.01 & 0.18 & 30 \\
\hline Tibet & 0.07 & 0.30 & 0.09 & 0.00 & 0.14 & 31 \\
\hline
\end{tabular}

From the analysis of overall ranking of S\&T innovation ability in China, it is concluded that Shanghai, Beijing, Guangdong, Zhejiang, Gansu and Jiangsu rank the top six in terms of S\&T innovation ability, among which the total score of Shanghai is 0.53 , ranking the top in China. And the provinces and cities that rank the last five rankings include Tibet, Qinghai, Chongqing, Ningxia and Heilongjiang. Generally speaking, it is found that the S\&T innovation ability has certain connection with the local economic development levels, but not absolutely related. For example, the GDPs of Gansu, Shaanxi and Xinjiang in 2015 ranks among the last six provinces in China, but the innovation ability of meteorological $\mathrm{S} \& \mathrm{~T}$ of these provinces is above the average line. What's more, 12 provinces and cities have the average score of 0.3 and 19 have the scores below the average. It can be seen 
that there is certain positive correlation between S\&T innovation environment and ability. Most provinces and cities that have S\&T innovation environment above the average line are the ones with high ranking of S\&T innovation ability. However, difference does exist, for example, though the S\&T innovation environment of Zhejiang and Anhui is poor, some other indexes are outstanding, hence the rankings of S\&T innovation ability are high.

\subsection{Overall evaluation of S\&T innovation environment}

As shown in the Overall Evaluation of S\&T Innovation Environment, 10 provinces are above the average line (0.28), including Jiangsu, Yunnan, Sichuan, Inner Mongolia and Guangdong, while 10 provinces are below the average line, including Tibet, Qinghai, Ningxia, Chongqing and Guizhou. Judging from the distribution of various indexes, the areas of developed economies own the high knowledge accumulation and have unique advantages in attracting and cultivating talents. Therefore, the overall scores of S\&T innovation environment in these areas are relatively higher. Shanghai has a large number of scientific research organizations.

Inner Mongolia has the most professional meteorological technicians in 10,000 people. The proportion of master's degree and above in the employee team in Beijing is the biggest. Activeness of trans-provincial meteorological data in Guangdong is the highest. Jiangsu owns the most volume of meteorological data sharing services.

\subsection{Overall evaluation of S\&T innovation input}

It can be shown from the overall score of S\&T input is negatively related to economy, which means that the more developed one province is, the lower expenditure on meteorological R\&D in GDP it has; the less developed one province is, the higher expenditure on meteorological R\&D in GPD it has. This can be explained because there exists larger gaps among different provinces in terms of the GDP incomes and the same increase of meteorological S\&T input in rich areas has more influence to the GDP than in under-developed areas. The results tell that the proportions of S\&T input in Shanxi, Guizhou, Ningxia, Jilin, Anhui, Heilongjiang and Shandong are higher; the proportions of S\&T input in Guangdong, Chongqing, Henan, Yunnan and Hubei are lower. In terms of the percentage of R\&D expenditure in GDP and annual growth rate of meteorological S\&T expenditure, Gansu ranks the top. In terms of meteorological S\&T expenditure by professionals per capita, Shanghai ranks the first. As for percentage of basic research in R\&D expenditure, Shaanxi has the highest. When it comes to applied research in R\&D expenditure, Shandong ranks the first.

\subsection{Overall evaluation of S\&T innovation uutput}

It is shown from 15 provinces and cities are above the average line $(0.27)$, while 16 are below the average line. Compared with other indexes, there are more provinces and cities with this index above the average line. Shanghai, Zhejiang, Jiangsu, Beijing and Xinjiang have the highest output values. Inner Mongolia, Tibet, Qinghai, Shandong and Henan have the least output values. The quantity of SCI papers in Shanghai, Jiangsu and Zhejiang is the largest; Xinjiang has the most of meteorological patents. Jiangxi and Hunan have the highest percentage of project participating staff in total employees, demonstrating that these two provinces have the highest activeness of scientific research.

\subsection{Overall evaluation of S\&T innovation efficiency}


we can see that Shaanxi, Guangdong, Zhejiang and Beijing are the provinces and cities with highest innovation efficiency. Tibet, Liaoning, Qinghai, Yunnan are with lowest innovation efficiency. 11 provinces and cities reach above the average line (0.26).

\section{Conclusion}

Due to the limitation of data source, the writer only chooses statistical data in the year of 2015. Consequently, it is difficult to embody the growth tendency and annual average innovation ability. Meanwhile, the selection of evaluation indexes is limited by data availability, which restricts further accurate level of the indexes. Therefore, the evaluation results may have slight differences from the actual conditions of the provinces and cities.

Through the empirical analysis of the innovation ability of meteorological S\&T in China, it is clear that Chinese domestic meteorological scientific research results are abundant and the innovation ability keeps improving in recent years. On the other hand, meteorological S\&T in different provinces and cities are growing with heavy imbalance and thus the development gap is still large from one region to another, for example, distribution of human resources of S\&T is uneven, input and output degrees of S\&T expenditures are imbalanced, and allocation of S\&T resources needs to be further optimized. However, it is notable that resource endowment differs from region to region, consequently, it still needs further discussion about whether the balanced development of S\&T innovation ability is really necessary at the national level or shall be promoted to different provinces and cities.

\section{Policy suggestions}

Based on the empirical researches of meteorological S\&T innovation ability and judging from the main findings from the evaluation process, the following policy changes are proposed:

\subsection{Enhance government policy direction, coordinate S\&T innovation ability among different regions}

Different areas have different economic strength and weakness, so does their S\&T innovation abilities. But S\&T input is not the most important index. For example, the S\&T input of Jiangsu is only 0.2 , lower than the average value of 0.38 , but its overall strength ranks the fourth. Moreover, S\&T inputs from Tibet, Qinghai and Ningxia are all higher than the average but these provinces have pessimistic overall strength. Thus, together with S\&T input factor, innovation environment, output and efficiency are also important indexes. When drafting its policies, the government shall not only pay attention to the input of R\&D expenditure, but also emphasize the factors such as how to attract S\&T talents into its own area, improve the degree and efficiency of S\&T data sharing, pay more attention to under-developed areas, focus on the common difficulties from different regions, and coordinate the improvement of overall strength of regional innovation.

\subsection{Strengthen S\&T input for the basic R\&D in meteorology}

The breakthrough and innovation of core technologies comes from the continuous input of basic research[7]. Some scholars made the statistics that the developed countries (the US, Japan and France) and the newly emerging developing countries have applied their research expenditure of up to $12 \%$ to $30 \%$ to the basic research areas, and most of such fund providers are the government. The development of meteorological S\&T cannot be separated 
from the researches of basic science. However, in terms of the input of basic research in China's domestic meteorological S\&T, basic research projects only occupied about $25 \%$ of the total projects while the applied research 53\% in the year of 2015. The applied researches and related product developments in the past years have occupied more than half of the total amount of R\&D. However, this continuous input to the applied researches has not significantly promoted the innovation of domestic meteorological S\&T, or made major technical breakthrough. Therefore, our focus should be to strengthen the continuous input of basic researches and the innovation strategy shall spot on autonomous R\&D in China.

\subsection{Pay attention to the opening and sharing of meteorological data}

Currently, both science and innovation have been developing with new characteristics: they become more internationalized and hold value close cooperation, and all the people may benefit from comprehensive innovations. when we study the sharing degree of meteorological data, the cooperation and sharing levels of meteorological S\&T are not high enough, because of these research findings in this paper: the average activeness of trans-provincial meteorological data in 2015 is only 0.213 (the maximum value is 1 ), the volume of meteorological data sharing services is as low as 0.126 (the maximum value is 1 ), the number of undertaken projects per capita on average is 0.44 (the maximum value is 1 ), and the project participating staff in total employees is only 0.32 (the maximum value is 1 ). Therefore, the sharing degree of meteorological data should be increased and the establishing of meteorological S\&T basic condition platform be accelerated, in order to reach enough high level of meteorological data opening and sharing.

\subsection{Strengthen the dominant role of enterprises in S\&T innovation}

Chinese government proposed to strengthen the dominant status and leading role of enterprise innovation in 13th Five-year National Science and Technology Innovation Plan. Data show that $60 \%$ of operation revenue of Apple in 2011 came from the innovative and recreational products such as iPhone and iPad[8]. During the research of innovation ability of meteorological S\&T, the writer also tries to study the innovation research ability of enterprises. However, seen from the available materials, the basic data about meteorological enterprise innovation is still insufficient, as there is no official statistics about the meteorological enterprise scales, their total production value, $R \& D$ input, and so on. In fact, the main body of Meteorological S\&T innovation still is institutes, the role of meteorological is very small.Consequently, it is difficult to judge the enterprises' role in the innovation of meteorological S\&T and to measure the enterprises' S\&T innovation ability in China. Policies are suggested to further strengthen enterprises' leading role in meteorological S\&T innovation, strengthen the baseline survey of the corporate scale and innovation ability, encourage and cultivate the development of new-type meteorological enterprises and further standardize the meteorological industry market.

\section{References}

1. Zhang Laowu, S\&T Innovation Drives changes in the Mode of Economic Development, China Soft Science [J], (2011) (12): 1-5.

2. Soumitra Dutta, Bruno Lanvin, and Sacha Wunsch-Vincent, The Global Innovation Index 2017 - Innovation Feeding the World [M], Cornell University, INSEAD, WIPO, (2017

3. Region[J], China S\&T Forum, (2007) (11): 21-24. 
4. Fan Hua, Zhou Dequn, Research on Evolution of Efficiency of S\&T Innovation in China's Provinces and Its Influencing Factors [J], Scientific Research Management, (2012) (33): 10-26

5. Song Jiekun, Song Qing, Evaluation of China's Provincial Input-Output Efficiency of S\&T [J], Journal of China University of Petroleum (Social Science Edition), (2014) (30): 16-20.

6. Huo Guoqing, Li Jie, Empirical Study on the Strategic Effect of Strategic Emerging Industries in China [J], China Soft Science, (2017) (1): 127-138

7. Liu Xielin, Basic Research Is the Source of China's Industrial Core Technological Innovation [J], China Soft Science, (2011) (4): 104-117

8. Xue Lan, The Development Trend of Strategic Emerging Industries in the World [J], China Soft Science, (2013) (5): 18-26 